\title{
BIODEGRADATION OF NICKEL AND CHROMIUM FROM STAINLESS STEEL CROWNS AND SPACE MAINTAINERS - AN IN VITRO STUDY
}

Vijaya Bhaskar B, VV Subba Reddy. Biodegradation of nick$\mathrm{el}$ and chromium from stainless steel crowns and space maintainers - an in vitro study, Annals Dent Univ Malaya 1997; $4: 17-21$

\begin{abstract}
The study was undertaken to analyse in vitro biodegradation of stainless steel crowns, and space maintainers (stainless steel band materials) by keeping the respective number of samples in the artificial saliva incubating at $37^{\circ} \mathrm{C}$. Nickel and chromium release after 1,7,14,21 and 28 days was analysed by using atomic absorption spectrophotometer. Results showed that there was statistically significant release of both nickel and chromium which reached maximum level at the end of 7 days and gradually reduced thereafter. The maximum release of nickel and chromium was much below than the dietary intake even for four crowns/band used and are not capable of causing any toxicity.
\end{abstract}

\section{INTRODUCTION}

In recent years there has been a dramatic increase in the use of metals and non-precious alloys in clinical dentistry. Austenitic steel alloys containing Nickel and chromium are used for making crowns, bands, wires, denture bases, space maintainers, brackets etc.

Nickel and chromium are two metals often used in the construction of various parts of most pedodontic appliances. Advantages of this Nickel chromium alloys viz; high strength, corrosion resistance and relative low cost have lead to their common use. This has raised questions concerning their biological safety. The potential health effects from exposure to nickel and chromium and their compounds have been scrutinized for more than 100 years, and it was established that these metals could cause hypersensitivity $(1,2,3,4)$, allergic dermatitis, asthma and ulcers of mucous membrane. $(5,6)$

The nickel one of the most common allergens and the most potent sensitizer of all metals has been described as "ubiquitous contact allergens".(7) It has been $\operatorname{shown}(2,6,8,9)$ that patients who are allergic to nickel will also react to certain nickel chromium dental alloys.

In pedodontics, the stainless steel crowns and space maintainers are widely used. These are made of base metal alloys containing mainly nickel and chromium as the main constituents. The oral environment is particularly ideal for the biodegradation of metals because of its ionic, thermal, microbiologic and enzymatic properties. Therefore the study was carried out to analyse in vitro the biodegradation of stainless steel crowns of three different companies (Ion, 3M Canada Incorporation, SS, Sankin, Japan) and space maintainers made of two different company bands (Dentaurum - Fed. Rep. Germany and Unitek - USA). Some level of patient exposure to the corrosion products of these alloys could be assumed, if not assured.
1 Vijaya Bhaskar B.

2 V. V. Subba Reddy, M.D.S., F.I.C.D. (USA), M.I.A.P.D. (USA)

1 Resident, Department of Pedodontia and Preventive Dentistry, Bapuji Dental College and Hospital,

Davangere - 577004

Karnataka, India

2 Professor and Head of the Department Department of Pedodontia and Preventive Dentistry, Bapuji Dental College and Hospital,

Principal,

College of Dental Sciences,

Davangere - 577004

Karnataka, India

\section{MATERIALS AND METHODS}

Thirty samples were selected out of which 10 belonged to Ion, 10 to Sankin and 10 to $3 \mathrm{M} \mathrm{SS}$ brands. Each group of 10 samples were further divided into 4 groups which is shown in Table I. Twenty space maintainers were studied out of which 10 were fabricated using Dentaurum and 10 using Unitek band materials.

Table I

$\begin{array}{clcl}\text { Group } & \text { No. of crowns } & \text { Group } & \text { No. of space maintainers } \\ \text { I } & - \text { One crown } & \text { I } & \text { - One space maintainers } \\ \text { II } & - \text { Two crowns } & \text { II } & \text { - Two space maintainers } \\ \text { III } & - \text { Three crowns } & \text { III } & \text { - Three space maintainers } \\ \text { IV } & - \text { Four crowns } & \text { IV } & \text { - Four space maintainers }\end{array}$

$1+2+3+4=1$ each

The test materials in each sub group both crowns and space maintainers were placed in separate glass beakers containing $100 \mathrm{ml}$ of artificial saliva at $37^{\circ} \mathrm{C}$ in an incubator for 4 weeks. The required amount of salivary samples were drawn out from each beaker and analysed separately on days 1, 7, 14, 21 and 28 using atomic absorption spectrophotometer.

Two different types of bands (Dentaurum - Fed. Rep. Germany and Unitek - USA) were chosen for making space maintainers as they were commonly used in pediatric dentistry. Each type of space maintainer is made onfirst permanent molar using similar casts. Dentaurum stainless steel wire was used for making loops and Unitek solder for soldering. Later they were trimmed and polished.

The simulated saliva medium was prepared by using 0.8 gm of $\mathrm{NaC} 1$ (Sodium chloride), $2.4 \mathrm{gm}$ of KC1 (Potassium chloride), $1.5 \mathrm{gm} \mathrm{NaH} \mathrm{PO}_{4} 2 \mathrm{H}_{2} \mathrm{O}$ (Disodium anhydrous 
phosphate), 0.1 gms $\mathrm{Na}_{2} \mathrm{~S}, 9 \mathrm{H}_{2} \mathrm{O}$ (Sodium sulphide), 2 gms $\left(\mathrm{CO}\left(\mathrm{NH}_{2}\right)_{2}\right)$ (Urea), $2000 \mathrm{ml}$ of distilled deionized water and albumin (Albumin bovine fraction $\mathrm{V}$ ). The $\mathrm{pH}$ of artificial saliva was adjusted to $6.75 \pm 0.15$ by adding in increments of $50 \mathrm{ml}$ of $10 \mathrm{~N}$ sodium hydroxide and it was measured by using E.Merch (D-6100 Darmstadt F.R. Germany) pH indicator papers with a high degree of sensitivity ( 0.2 units sensitivity).

The analysis was performed with an atomic absorption spectrophotometer 1800 Hitachi Model which is based on the unique spectrum of each element. For every element anlaysed, characteristic wavelengths are generated in a discharge lamp (hollow cathode lamp), and in turn are absorbed by a cloud or vapour of that element. The amount of absorption is proportional to the concentration of the element that is vaporized into the light beam. Since the sensitiveness of the equipment was restricted upto 1 ppm a "standard addition method" was used.

\section{PROCEDURE:}

$20 \mathrm{ml}$ of known concentration and nickel ( $6 \mathrm{ppm})$ is taken. It is analysed by using atomic absorption spectrophotometer. A standard graph is plotted. $10 \mathrm{ml}$ of known concentration of nickel is added to $10 \mathrm{ml}$ of saliva test sample. The values were recorded for the released metal. The values dropped down drastically indicating the very presence of deionized water which made the solution to dilute. To analyse the exact amount of metal released, a standard solution of $10 \mathrm{ml}$ of known concentration of nickel was added to $10 \mathrm{ml}$ of deionised water. Again the analysis was performed, the ppm was below the salivary sample level. It indicated that the standard solution, was diluted because of deionised water showing a lesser ppm level. Finally the difference between the two (standard solution with saliva - standard solution with deionised water) revealed the exact amount of nickel released.

For each sample analysis was done 3 times and an average was taken to obtain the accurate results.

Same procedure was carried out for chromium release by using standard solution (5 ppm).

The results were statistically analysed by using following formulae;

Analysis of Variance Snedecor's F test :

$\mathrm{F}=\frac{\text { Between group variance }}{\text { Within group variance }}$

Studentized Range test :

Minimum Significant range

$$
\begin{aligned}
& \mathrm{K}=\mathrm{K}^{*} \\
& \begin{array}{cl}
\mathrm{Ve} & \mathrm{K}^{*}-\text { Table value } \\
\mathrm{Nm} & \mathrm{Ve}-\text { Error variance } \\
\mathrm{Nm}-\text { Sample size }
\end{array} \\
& \text { Mean }=\frac{\sum X_{i}}{n} \\
& \mathrm{i}=1
\end{aligned}
$$

\section{RESULTS}

The release of nickel and chromium in Group I, II, III and IV crowns were shown in Tables II. In all the cases the release of nickel and chromium reached maximum on 7 th day thereafter it diminished with time. The comparison of total release of Nickel and Chromium showed that the amount of nickeland chromium release were proportional to the number of crowns. The release of the materials from sankin product was more in comparison with the release from ION and 3M SS Company USA).

Fig. I: Total Release of nickel in Group I, II, III and IV crowns

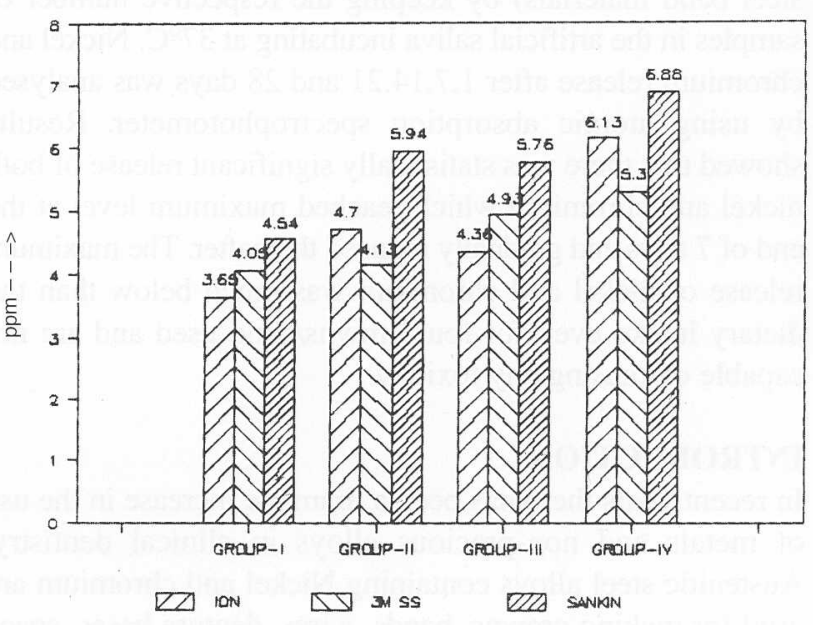

Fig. II: Total Release of chromium in Group I, II, III and IV crowns

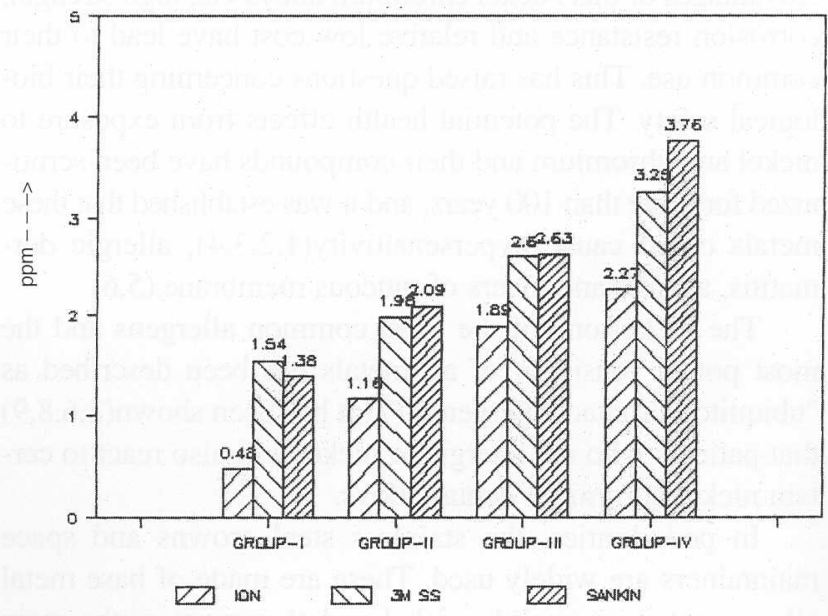

The release of nickel and chromium in Group I, II, III and IV space maintainers were shown in Tables III. In all the cases the release of nickel and chromium reached maximum on 7 th day thereafter it diminished with time. It can also be seen that the total release of nickel and chromium were proportional to the number of space maintainers. The product of dentaurum showed more release of Nickel compared to Unitek, while the release of chromium was found in Unitek. 
Table II

Release of nickel and chromium in Group I, II, III and IV (One, two, three and four crowns in saliva) at 1, 7, 14, 21 and 28 days

\begin{tabular}{|c|c|c|c|c|c|c|c|c|c|c|c|c|}
\hline & & GROUP I & & & GROUP ॥ & & & GROUP III & & & GROUP IV & \\
\hline Day & ION & 3M S.S. & SANKIN & ION & 3M S.S. & SANKIN & ION & 3M S.S. & SANKIN & ION & 3M S.S. & SANKIN \\
\hline
\end{tabular}

Nickel Chromium Nickel Chromium Nickel Chromium Nickel Chromium Nickel Chromium Nickel Chromium Nickel Chromium Nickel Chromium Nickel Chromium Nickel Chromium Nickel Chromium Nickel Chromium

\begin{tabular}{cccccccccccccccccccccccccccccccccccc}
\hline 1 & 0.82 & 0.09 & 0.98 & 0.47 & 1.16 & 0.39 & 1.44 & 0.27 & 0.92 & 0.62 & 1.46 & 0.46 & 0.95 & 0.50 & 1.04 & 0.76 & 1.47 & 0.61 & 1.80 & 0.44 & 1.15 & 0.78 & 1.75 & 0.74 \\
\hline 7 & 1.16 & 0.25 & 1.33 & 0.75 & 1.59 & 0.47 & 1.40 & 0.38 & 1.36 & 0.78 & 1.66 & 1.06 & 1.32 & 0.61 & 1.68 & 0.86 & 1071 & 1.07 & 2.09 & 0.81 & 1.68 & 1.23 & 2.21 & 1.19 \\
\hline 14 & 0.82 & 0.14 & 0.93 & 0.22 & 0.92 & 0.34 & 0.85 & 0.31 & 0.94 & 0.40 & 1.28 & 1.34 & 0.99 & 0.43 & 1.06 & 0.44 & 1.32 & 0.49 & 1.03 & 0.59 & 1.14 & 0.57 & 1.38 & 0.89 \\
\hline 21 & 0.49 & 0.00 & 0.46 & 0.06 & 0.43 & 0.05 & 0.51 & 0.16 & 0.53 & 0.12 & 0.74 & 0.07 & 0.57 & 0.19 & 0.58 & 0.29 & 0.76 & 0.14 & 0.62 & 0.24 & 0.72 & 0.36 & 0.86 & 0.51 \\
\hline 28 & 0.36 & 0.00 & 0.35 & 0.04 & 0.44 & 0.13 & 0.50 & 0.04 & 0.38 & 0.06 & 0.48 & 0.16 & 0.53 & 0.16 & 0.57 & 0.29 & 0.50 & 0.32 & 0.59 & 0.19 & 0.61 & 0.31 & 0.62 & 0.43 \\
\hline
\end{tabular}

Total

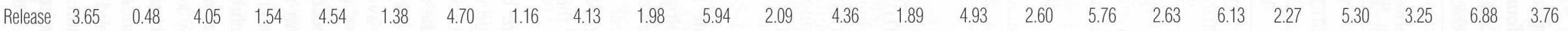

(ppm)

Per day

$\begin{array}{lllllllllllllllllllllllll}\text { Release } & 0.13 & 0.02 & 0.15 & 0.05 & 0.16 & 0.049 & 0.18 & 0.04 & 0.15 & 0.07 & 0.21 & 0.08 & 0.16 & 0.07 & 0.18 & 0.09 & 0.21 & 0.09 & 0.22 & 0.88 & 0.19 & 0.12 & 0.24 & 0.13\end{array}$

(ppm)

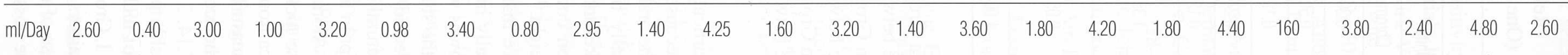

A) Release of Nickel between days was statistically significant showing $P<0.01$. Whereas for Chromium there was statistically significant difference between days as well as materials showing $P<0.0 .5$.

B) The elease of Nickel between days and materials was statistically significant showing $\mathrm{P}<0.05$. Whereas for Chromium the release between the days was statistically significant showing $\mathrm{P}<0.0 .1$.

C) The elease of Nickel between materials was statistically significant showing $\mathrm{P}<0.05$ and between days $\mathrm{P}<0.01$. Whereas for Chromium the release between the days was statistically significant showing $\mathrm{P}<0.0 .1$.

D) The elease of Nickel between materials was statistically significant showing $P<0.01$ and for the days showeing $P<0.001$. 
Table III

Release of chromium and nickel in Group I, II, III and IV S.M.

(One, two, three and four S.M. in saliva) at 1, 7, 14, 21 and 28 days

\begin{tabular}{|c|c|c|c|c|c|c|c|c|c|c|c|c|c|c|c|c|}
\hline \multirow{3}{*}{ Day } & \multicolumn{4}{|c|}{ Group I } & \multicolumn{4}{|c|}{ Group II } & \multicolumn{4}{|c|}{ Group III } & \multicolumn{4}{|c|}{ Group IV } \\
\hline & \multicolumn{2}{|c|}{ Dentaurum } & \multicolumn{2}{|c|}{ Unitek } & \multicolumn{2}{|c|}{ Dentaurum } & \multicolumn{2}{|r|}{ Unitek } & \multicolumn{2}{|c|}{ Dentaurum } & \multicolumn{2}{|c|}{ Unitek } & \multicolumn{2}{|c|}{ Dentaurum } & \multicolumn{2}{|c|}{ Unitek } \\
\hline & Nickel & Chromium & Nickel & Chromium & Nickel & Chromium & Nickel & Chromium & Nickel & Chromium & Nickel & Chromium & Nickel & Chromium & Nickel & Chromium \\
\hline 1 & 2.10 & 0.01 & 1.10 & 0.30 & 1.87 & 0.03 & 1.37 & 0.70 & 1.25 & 0.19 & 1.82 & 0.63 & 2.31 & 0.58 & 1.96 & 1.36 \\
\hline 7 & 2.46 & 0.52 & 1.54 & 0.50 & 2.41 & 0.63 & 1.74 & 0.70 & 2.24 & 0.76 & 2.02 & 0.78 & 2.50 & 0.80 & 2.31 & 1.41 \\
\hline 14 & 1.23 & 0.31 & 1.28 & 0.19 & 1.31 & 0.46 & 1.34 & 0.57 & 1.37 & 0.65 & 1.44 & 0.60 & 1.41 & 0.70 & 1.48 & 1.00 \\
\hline 21 & 0.58 & 0.25 & 0.73 & 0.24 & 0.68 & 0.34 & 0.81 & 0.34 & 0.76 & 0.45 & 0.95 & 0.34 & 0.87 & 0.57 & 1.00 & 0.50 \\
\hline 28 & 0.37 & 0.17 & 0.30 & 0.15 & 0.41 & 0.24 & 0.50 & 0.15 & 0.66 & 0.25 & 0.51 & 0.22 & 0.69 & 0.37 & 0.73 & 0.27 \\
\hline $\begin{array}{c}\text { Total } \\
\text { Release } \\
(\mathrm{ppm})\end{array}$ & 6.74 & 1.26 & 4.95 & 1.38 & 6.68 & 1.70 & 5.76 & 2.46 & 6.98 & 2.30 & 6.74 & 2.57 & 7.78 & 3.02 & 7.48 & 4.54 \\
\hline $\begin{array}{l}\text { Per day } \\
\text { Release } \\
(\mathrm{ppm})\end{array}$ & 0.24 & 0.04 & 0.18 & 0.05 & 0.24 & 0.06 & 0.21 & 0.09 & 0.25 & 0.08 & 0.24 & 0.09 & 0.28 & 0.11 & 0.27 & 0.16 \\
\hline ml/Day & 4.80 & 0.90 & 3.60 & 1.00 & 4.80 & 1.21 & 4.20 & 1.76 & 5.00 & 1.60 & 4.80 & 1.80 & 5.60 & 2.20 & 5.40 & 3.20 \\
\hline
\end{tabular}

The release of Nickel in Group II S.M. showing statistically significant difference between the days $\mathrm{P}<0.01$.

The release of Nickel in Group III S.M. showing statistically significant difference between the days $\mathrm{P}<0.01$.

The release of Nickel in Group IV S.M. showing statistically significant difference between the days $\mathrm{P}<0.01$.

\section{DISCUSSION:}

The oral environment is particularly ideal climate for the biodegradation of metals because of its microbiologic and enzymatic phenomena. In the oral environment biodegradation of metals occurs usually by electrochemical breakdown. ${ }^{(10)}$ The amount of nickel and other metals released due to electrochemical corrosion could never reach the toxic dose of $10 \mathrm{ppm} / \mathrm{kg}$ body weight. ${ }^{(11}$

Maximum of four space maintainers and four crowns were grouped because, usually in a patient average of four space maintainers or four crowns will be given. Artificial saliva was used as medium in the study to simulate the natural saliva and albumin was selected as the protein component because of its presence in natural saliva and ready availability. All the samples were kept in a incubator at $37^{\circ} \mathrm{C}$ to simulate the oral temperature. Atomic absorption spectrophotometer was used to analyse nickel and chromium release because other analysis like calirometric analysis and ultraviolet spectrophotometer to measure the nickel and chromium levels below $1 \mathrm{ppm}$. So for the accuracy and convenience we measured the levels on 1, 7,14, 21 and 28 days by keeping each group in $100 \mathrm{ml}$ of freshly prepared artificial saliva.

The maximum release of nickel and chromium at 1, 7, 14, 21 and 28 days in Group I, Group II, Group III and Group IV crowns and space maintainers showed maximum on 7 th day and thereafter the release of nickel and chromium was progressively decreased. The possible explanation would be
Fig. I: Total Release of nickel in

Group I, II, III and IV space maintainers

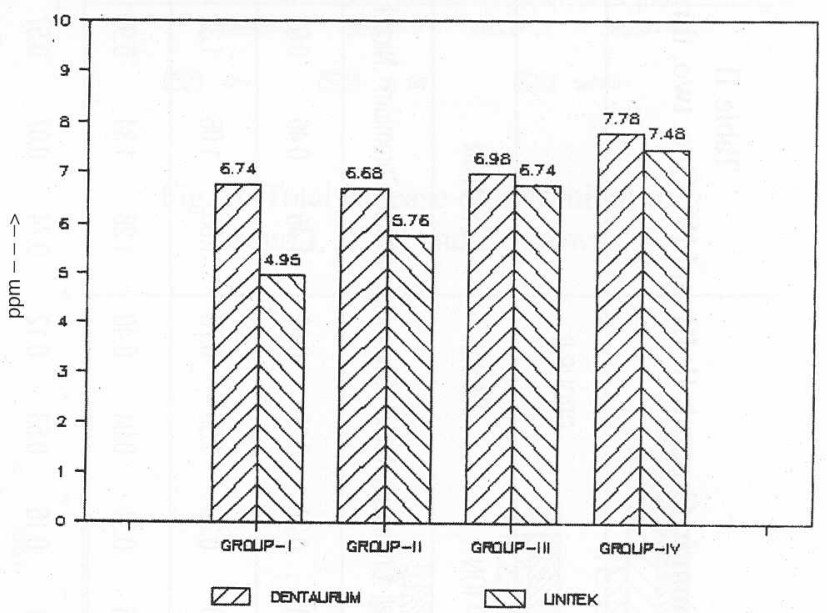

Fig. II: Total Release of chromium in Group I, II, III and IV space maintainers

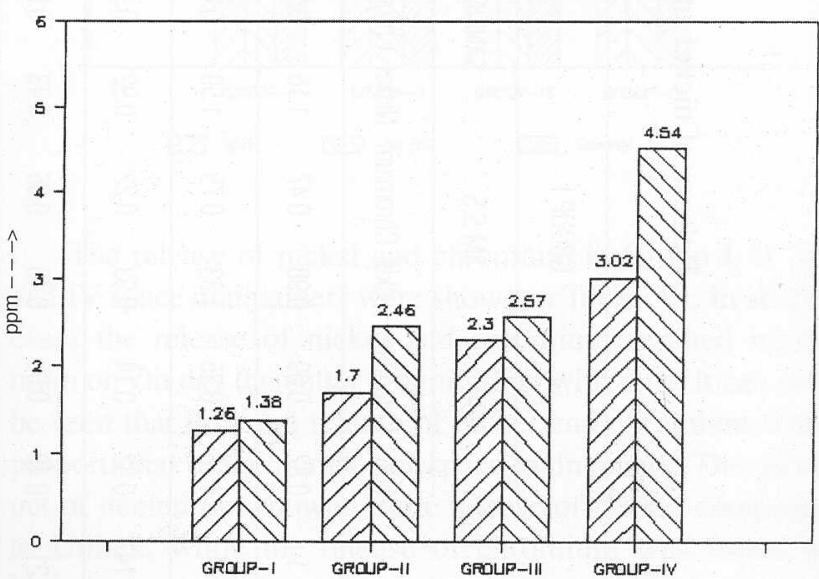


nickel and chromium present on the surface of the crowns my quickly corrode during the first 7 days of the experiment, then the rate of release drops off as the surface chromium is depleted.

The release of nickel and chromium were directly proproportional to the number of crowns or space maintainers in the artificial saliva. This may be because with the increase in the number of crowns or number of space maintainers the available context of nickel and chromium was increased for corrosion. All these values were much below than the average dietary intake of nickel 200-300 ppm/day and chromium $280 \mathrm{ppm} /$ day. ${ }^{(12,13)}$

Out of all the three company crowns Sankin crowns showed relatively high release of Nickel and Chromium than the Ion and 3M SS crowns. The reason for this may be because of the difference in the composition and manufacturing process and the same was observed by Margret Rosa et al in 1994. ${ }^{(14)}$

There was no significant difference between the space maintainers made with different company bands.

WHO, $1988^{(15)}$ and $1991^{(16)}$ stated that $0.2 \mathrm{ppm} / \mathrm{kg}$ body weight of nickel and $50 \mathrm{ppm} / \mathrm{kg}$ body weight of chromium can cause systemic manifestations. But in this study all the released nickel and chromium values were very much less than the values to cause any toxicity.

Overall the space maintainers showed more higher release than the crowns. This may be because of the solder used and also because of the heat used for the soldering and the same was reported by Margret Rosa et al in 1992. ${ }^{(14}$

It has been observed ${ }^{(17,18)}$ that there is increased sensitivity of nickel in females because of costume jewellery used by them containing nickel has been found to be responsible for a significant number of nickel hypersensitivity. In case of history of nickel and chromium sensitivity, an alternate alloy should be recommended. A patch test could be performed before selecting nickel and chromium containing alloys.

\section{CONCLUSIONS:}

Base metal alloys used in the pediatric dentistry i.e. Stainless steel crowns and band and loop space maintainers release measurable amount of the nickel ranging from (3.65 to 6.88 ppm for Crowns, 4.95 to 7.78 ppm for S.M.) and chromium (0.48 to $3.76 \mathrm{ppm}$ for Crowns, 1.70 to $4.54 \mathrm{ppm}$ for S.M.) in an artificial salivary medium. Both nickel and chromium release reaches a peak level on 7 th day, then the rate of release diminishes with time.

The release of nickel and chromium very much below when compared with the average dietary intake of nickel (200-300 ppm/day) and chromium (280 ppm/day) which were not capable of causing any toxic efffects. Even though Sankin crowns released more amount of nickel and chromium it was not statistically significant. There was no significant difference of release between the space maintainers made with different band materials.

In case of history of nickel and chromium sensitivity an alternate alloy should be recommended and a patch test could be performed before selecting nickel and chromium containing alloys

\section{REFERENCES}

1. Burrows. D. Hypersensitivity to nickel and chromium in relation to dental materials. Int. Dent. J. 1986; 36 : 30-34.

2. Charles L. Dunlap, Kirk Vincent, Bruce F.B. Allergic reaction to orthodontic wire - Report of case. J Am Dent Assoc. 1989; $118: 449-450$

3. Moffa J.P., W.D. Beck. Allergic response to nickel containing dental alloys. J Dent Res. 1997; 56 : B. 78 Abst. 107.

4. Temesvari E and I Racz. Nickel sensitivity from dental prosthesis - Contact Dermatitis. 1988; 18 : 50-51.

5. Arne Hensten - Peterson. Casting alloys : Side effects Adv Dent Res 1992; 6 : 38-43.

6. Darwin L. Brendlinger, John J. Tarsitano. Generalised dermatitis due to sensitivity to a chrome cobalt removable partial denture. J Am Dent Assoc. 1970; 81 : 392394.

7. Covington J.S., A.L. Disney. Quantization of nickel and beryllium leakage from base metal alloys. JPD. 1989; $54:$ 127-136.

8. Feasby W.H., Ecclestone E.R., Grainger R.M. Nickel sensitivity in pediatric dental patients. J Pediatric Dent. 1988; $10: 127-129$.

9. Fernandes J.P., C. Veron et al. Nickel allergy to dental prosthesis - Contact Dermatitis. 1986; 14 : 312.

10. Rolf Maijer. Biodegradation of the orthodontic rackett system. Am.J. Orthodon. Dentofacial Orthop. 1986; 90: 195-198.

11. De Michell, Riesgo-LE. Comportement electrochinique de Alliages Dentaire $\mathrm{Co}-\mathrm{Cr}$ at $\mathrm{Ni}-\mathrm{Cr}$ utilises en Prosthese : Fuxee Rev. D'Odonto Stomatol. 1978; 7 : 349-353.

12. Robert D. Barrett, Janice K. Quinn. Biodegradation of orthodontic appliances Part I. Biodegradation of nickel and chromium in vitro. Am.J. Ortho. Dentofac. Orthop. 1993; 103 : No. $1: 8-14$.

13. Samir E. Bishara and Moustafa I. Selim. Biodegradation of orthodontic appliances - Part II Changes in the blood level of Nickel. Am. J. O. 1993; 103 : 115-119.

14. Margret Rosa Grimsdottir, Cand Odont, M.S., Nils Gjerdet Dr. Odont. Composition and in vitro corrosion of orthodontic appliances. Am. J. Orthod. Dentofac. Orthop. 1992; 101 : No. $6: 525-532$.

15. IPCS : International Programme on chemical safety environmental health criteris. 61-chromium (WHO). 1988; $15: 110-120$.

16. IPCS. International Programme on Chemical safety environmental health criteris. 108-nickel (WHO). 1991; 16-17.

17. Workshop. Biocompatibility of metals in dentistry. National Inst. of Dent. Res. J Am Dent Assoc. 1984; 109 : 469-71.

18. Timothy K. Jones and Harvey P. Kesler. Dental implications of nickel hypersensitivity. JPD. 1986; 56 : 507509 . 